\title{
THE QUEERING OF BIBLICAL DISCOURSE
}

\author{
Johannes N Vorster \\ Biblical and Ancient Studies \\ University of South Africa
}

\begin{abstract}
This article explores certain conditions that should be taken into consideration in exploring the possibilities of a queering of biblical discourse. Following Butler it suggests that queering can be seen as a "kind of gender performance" that "will enact and reveal the performativity of gender itself in a way that destabilizes the naturalized categories of identity and desire" (1990:177). I argue that as a performativity of gender, the queering of biblical discourse requires a shift from text to discourse, and must insist on dissent and disruption.
\end{abstract}

Key Words: Queer Theory, Queer, Textual Agency, Biblical Discourse, Gender Performativity, Disruption Sexual Normatives

\section{Introduction}

In 1983 a twenty-one year old woman is raped in a tavern in New Bedford, Massachusetts, with 20 male patrons looking on without any intervention at all. In a remarkable charcoal composition Sue Coe represents this incident in Gray Rape, depicting a naked female woman, spread out with arms and legs on a pool table, two men at the top end pinning down her arms, another holding her by the hair, while a row of men in different stages of undressing prepare to rape her. The rest of the men remain impassive, faces expressionless as if nothing is happening. The woman has undeniably been composed in cruciform, confirmed by the writhing, agonising fingers of the hands replicating in almost exact form the hands and fingers of Christ in Grunewald's Isenheim Crucified Christ (Meyer 1997:25).

Gazing at this composition, sensing the ambiguity evoked by the engendered inversion of one of the main symbols of heteronormative Christianity leaves one with a lingering uncertainty and uneasiness. On the one hand, there is the reminder of the still rampant brutality of phallocraticism in contemporary society, resting impassively in the certainty of its dominating position, here represented by the violence of the gang rape and the inactivity of male viewers; on the other hand, there is the reminder of women embodying suffering via the evocation of Christianity's primary symbol of suffering. Taking the dramatic effect of this representation into account and its mediation into the sphere of the public via a complete re-signification of one of the primary motifs of the Bible, the question arises whether biblical scholars should not engage upon a radical rethinking of their discipline, and whether gender should not be the framework from which the categories can be derived in this process. If the study of the Bible is to be seen as an academic enterprise, should its deployment in contemporary discourses not also function as object of study? And since gender can no longer be seen as an approach among others, $a$ way of interpretation, but rather as an analytic and constitutive category of every approach to the Bible, should the manner in which the materialisation of bodies takes place, also in constant contemporary recourse and reference to the Bible not be part and parcel of its task?

The engendering of biblical discourse has been part and parcel of the academic study of the Bible since the advent of feminist interpretations of biblical writings. The advent of 
Queer Theory has provided new possibilities, compelling studies of the Bible to recognise how biblical discourse has been deployed in a multitude of ways in the cultural construction of gender. A comprehensive account of how gender performance and culture interacts cannot be provided, but I wish to demonstrate how the 'queering' of biblical discourse may compel cultural engagement and an analysis of its formative constituents, how it can enable the destabilisation of gendered normative claims on naturalisation and normalisation. In the interaction of Cultural Studies and Pedagogy, Henry Giroux has set as objective the development of Pedagogy as performative practice whereby a diversity of cultural texts are engaged "as a context for theorizing about social issues and wider political considerations" (1997:2). The question is, to what extent would it be possible that the queering of biblical texts could be used to 'think' politics with under-performativity as articulating principle. In the first section attention will be paid to theoretical issues concerned with queering as a performativity of gender, and I submit that the tension in the designation 'queer' also translates into its political agenda. In the second section, I problematise the queering of biblical texts and argue for the removal of textual agency as condition. In a third section, two further conditions are elaborated for a queering of biblical material.

\section{The Performativity of Gender}

While paying attention to the possibility of the subversive in parody, Butler asks inter alia: "[W]hat kind of gender performance will enact and reveal the performativity of gender itself in a way that destabilizes the naturalized categories of identity and desire?" (1999:177). To an extent she responds to this question with a question also phrased as a proposal a few years later when in referring to Sedgwick she asked "how it is that "queering' persists as a defining moment of performativity?" (1993:224). ${ }^{1}$ One could of course also ask whether the term, 'queering' (what after all, is in a name?) should be given this status and whether the same cannot also be said of Gender Criticism and Feminism. Would it be fair to contour 'Queer Studies' as a separate object of study in distinguishing itself from approaches such as Gay and Lesbian Studies when these approaches must clearly have been constitutive in the formation of Queer Studies? ${ }^{2}$ On the other hand the adoption of the designation 'queer' provides a specificity which lends a sharp edge to the performativity of gender. Perhaps the best route would be to acknowledge that the performance of 'queering' should not be seen as having arrived only when Queer Studies emerged as an object of study, but can be detected in a variety of works prior to its more formal recognition. ${ }^{3}$ However, irrespective of the origins of Queer Studies, 'queering' can

Here I have used Butler's 1999 edition of Gender Trouble: Feminism and the subversion of Identity which was first published in 1990.

2 See in this regard Schneider (2000:3) who reviews the relationships between homosexuality, queer theory and Christian theology and exhibits a keen sense of the fluidity of boundaries between these fields of study. Although he distinguishes gay, lesbian, bisexual, and transgendered studies by referring to their agenda of obtaining liberation, inclusion and justice he also indicates to what extent there is an overlap in interests (2000:4). See in this respect also Punt (2000:30) who points to the tendency of claims on naturalness among some expressions of homosexuality and some voices of radical feminists suspicious of Queer Theory's political commitment.

3 Schneider (2000:3) appears to assign the emergence of Queer Theory to Foucault (see also Punt 2006:30), and specifically to the appearance of the first volume of his History of Sexuality, emphasising the social and historical contingency of sexuality. Foucault's contribution to the formation of this space cannot be denied, but it is problematic to put him into the role of the originator, not only because that would contradict his problematisation of the subject's agency in the production of knowledge, but also and especially because it overlooks the variety of spaces from which Queer theoretical discourse emerged. Gayle Rubin's (2010:15-48) reflection on the socio-political context in which her 'Thinking Sex' first appeared testifies to the multiplicity 
indeed be seen as a mode of gender performativity that exposes how bodies, identities and desires have been constructed as normal and natural, while at the same time it signifies how gender can be performed in the destabilisation of normative, naturalised engendered structures. To refer to Butler again when she writes: "If the performative operates as the sanction that performs the heterosexualization of the social bond, perhaps it also comes into play precisely as the shaming taboo which 'queers' those who resist or oppose that social form as well as those who occupy it without hegemonic social action" (1993:226).

The deconstructive effect of using the term 'queer' has been astounding. The performative '(I) pronounce you queer,' was used to insult, declare a person peculiar, create an identity that was unfit, not normal, pushed to societal margins, even turned into an 'outsider,' while at the same time it confirmed and consolidated hegemonic heteronormativity, albeit as expressive of its homophobic tendencies. Power, not as subject but constituted by a constant reiteration of this type of speech act which derives its performative power from the citation of a norm, in this case heteronormativity, operated as discourse bringing into existence what it has named. A pathologized personage has been brought into existence performing as an 'anti-ideal,' allowing for the illusion of a fixed identity, bodies surrendered to a particular interiority, sometimes noted as an 'orientation,' 'inclination,' 'desire,' which the body surface betrays not only in its sheer physical composition, but also in posture, gesture, manner and behaviour.

And yet, the very same term is used to resist and invert the flow of power. Through the use of the same terminology that sought destruction, power counter-acts as a discourse of dissent with impressive efficiency, not only to mock and ridicule as in initial phases, but also to demarcate a site of theoretical reflection. The radicalness of this inversion should not be overlooked. If it is by the 'invocation of convention,' or the citation of the norm that a speech act derives its performative power as Butler (1993:225) would have us believe, this self-naming constituted a full-frontal offensive, exposing the fragility of hegemonic heteronormativity and more recently also homonormativity. Via the agency of this term, power has not only been constrained but has also enabled an expansion of discursive possibilities. Resisting capture and incorporation into a particular, fixed identity, such as gay or lesbian, queering functions as a performance of gender allowing us entry into the gendered pervasiveness of values and norms that have not only structured societies, but also functioned and function as beacons of aspirations. ${ }^{4}$

of forces combining in the production of an object of knowledge, as can be seen in the references to the stagings of protest actions by anti-pornographic feminists, major conferences, minor seminars, publications, but even by attempts of the academic bureaucracy's deployment of exclusionary measures under the pressure of public hysteria. And she takes us back to the early days of social constructionism when the agency of the subject was hailed in the glorification of 'glorious ancestors' and the stability of discourse. Garton (2004:2223) also refers to the larger contexts of economics, race, gender and class, and to the effects of the emerging interest in social history, already in operation in the 1960's and 1970's and advanced by people such as Jeffrey Weeks, also forming and shaping towards the field that would become Queer Studies. As a matter of fact, Weeks himself confirms that "we owe little at the beginning to Michel Foucault" and proceeds to show that what has to become known as social constructionism was already present before Foucault (2005:186201). And both Weeks and Garton point us to the role that Mary McIntosh's 'The Homosexual Role' has played in the historically restricted definition of the category 'homosexuality' already originally published in 1968 (Garton 2004: Weeks 2005:189). Explicitly referring to the term 'queer,' McIntosch confirms to what extent a different set of questions have to be asked, thereby opening the possibility for the beginning of a new field of enquiry (1968:182-192). Instead of situating Foucault as primary originator of this field, the sociopolitical forces, resisting its emergence as well as dissenting groups and voices, the role of conflict and the confrontational should be recognised as labouring towards the production of this field of knowledge.

4 See for example the rush towards colonial archives that Arondekar points to (2005:11), but who also indicates its restrictedness compelling to even wider and more areas (14-15); Loughlin (2008: 144), indicating how the 
There is therefore in this term a particular tension, perhaps even an ambiguity, which can also be seen in its agenda. On the one hand, corresponding to its societal repudiation, its primary feature can be seen as that of dissent and transgression. On the other hand, the dissent takes place by virtue of the very same injurious sexual normatives that have cast them into a marginalised position. The marginalisation effected by society's sexual normatives is not suspended, but demarcated as locus for the offensive. I will first focus on the dimension of dissent and then briefly pay attention to how use is made of the available discourses. Since performativity concerns the manner in which power functions as discourse and since performative discourse brings into existence what it names, and since hegemonic, heteronormativity has identified 'queerness' with difference, with transgression, with 'otherness,' even with indecency, this status has not only been accepted but claimed as a right and a challenge to the totalitarian and universally acclaimed regime of heteronormativity, and it is in this non-denial, yet challenge that discourses of dissent are produced.

That the notion of queer must be identified with dissent, and that the genealogy of Queer Theory displays in the formation of its object of study dissent and the destabilisation of naturalness and normativities can be seen in the passionate rhetoric of Gayle Rubin (2010:15-48) in rethinking the varied circumstances of its beginnings, in what can be described as a rhetoric of conflict and dissent. ${ }^{5}$ Schneider (2000:3) confirms this resistance and dissent when he compares the force of the term 'queerness' with gay, lesbian and homosexual and comes to the conclusion that "[q]ueerness is therefore something more transgressive, more productive of difference, and more disruptive of stable, normative sexual identities than what we think of when we use the terms gay, lesbian, or homosexual." As a matter of fact Queer Theory "does threaten the whole fabric of social meaning that heteronormativity has provided for the modern world" (4).

As the resisting power of queer discourse responds to the expectation of exposing how the performativity of gender has functioned in producing gendered identities and social hierarchies, it becomes apparent how widespread and concealed heteronormativity has pervaded societal discursive practices. The examples and spheres are too numerous to cover, but one area is that of current economics and the manner in which marriage and family life has been forced into complicity with neo-liberal capitalism. Jakobsen shows how the discipline of marriage has been embedded within a Protestant Reformist configuration of the autonomous individual, household and calling since the days of Calvin. She argues that sexual relations within marriage should not be seen as simply symbolic of

'insult turned' refers to the restrictedness of 'gay' in comparison with 'queer,' articulating its centrality 'to culture at large,' and then also delving into the literary past to elevate some authors (145) and eventually into church history; Edgardh (2009:43) who also shows how the term's inversion to address normativisation has allowed for a wider range of deployment than 'gay' and 'black' studies.

5 Examples of this type of resisting rhetoric can be seen in 'blood under the bridge' (15), 'attack on' (16, 23, $25)$, 'venomous treatment,' 'protests against' $(16,27,31,32,35)$, 'opposition' (16, 33), 'public enemy' (16), 'imploded,' 'feminist sex wars' $(17,20,27)$, 'lurking menace' (17), 'outrage,' 'noisy protest,' antagonist' (21), 'archictects of the leaflet and protest' (22), 'antipornography crusaders' (23), 'defense'( 25,35$)$, 'plunged right in' (26), 'skirmishes,' 'conflict' $(28,40)$, 'tensions' (31), 'confrontation,' 'pitched battle' (34), 'blasted' (35); see also Jeffrey Weeks (2005:186-201), specifically 'grassroots revolution, a revolution in everyday life," which is depicted as an 'unfinished revolution,' and a 'fierce contestation' (193); homosexuality which is seen as a central component of 'cultural wars,' a 'gay revolution' whose success provoked an 'opposition' (193), of which fundamentalism forms a movement dear to the 'sound of history marching on' (194); identity politics which has produced a "queer revolt against the tyranny of identities," culminating in an 'explosion' of identities (194); and the current situation is seen as a 'contemporary sexual battlefield' (194). 
"capitalist discipline and values," its reproductive possibilities not as "analogous to that of production," but as part of the "relations of production." She writes: "Sexual relations, when organized in terms of the Protestant ideal of marriage, are the materialization of the value of freedom" (Jakobsen 2012:27). In a similar manner Handley shows by revisiting nineteenth century court cases concerned with plural marriage and current debates on gay marriage show (in the wake of Jakobsen) how the "naturalization of certain kinds of (imagined) sex is transposed in America onto a naturalized set of property-based contractual relationships that are themselves read as constitutive of American national identity" (95). When other formations in history then emerge it is this national American identity that is threatened with the result that they are portrayed as "subversions of good order." A final example, yet still within the sphere of economics, concerns the rhetoric of the current recession. Working within a field referred to as "sociality-in-differentiation," Joseph $(2012: 134)^{6}$ problematises the rather unifying rhetoric referring to the recession as a 'financial crisis,' and an uncomplicated reference to 'mainstreet,' or 'the problem' that is seen as a matter of irrational decision making. Bodies subject to the compelling forces of normativities shift into focus when she writes: "[W]e see that people have been engaged in diverse struggles, over time (not in one particular crisis moment), to make viable lives, to cobble together resources that have enable fulfillment of - and occasionally resistance to norms. We see the ways those efforts have made them available for exploitation and invited them to exploit others" (134), and she shows how the appeal to the behaviour of bankers to take 'moral' responsibility and not to 'walk away' may be an appeal not to walk away from "a home that figured (in) a gendered, raced, sexualized American Dream," thereby confirming heteronormativity. Sufficient to show how the performativity of gender in its destabilising of naturalness, normality, hetero- and homonormativity, has been used as a discourse of dissent and resistance.

I have indicated that there is a particular tension in the term 'queer' that translates into its discursive agendas. On the one hand power (in particular naturalised gendered power) constructs queerness as a discourse of transgression making exclusion possible while consolidating the naturalness claim of heteronormativity; on the other hand, it evokes in the very same 'queering' an inversion, a constraint via a discourse of dissent, disrupting claims on continuity into discontinuity and producing differentiations. The resistance and dissent do not entail a rejection of the term. As a matter of fact it is via this very term that the counter-claims of denaturalisation and destabilisation are made. Yet despite claiming this term for the project of resisting regimes of hetero- and homonormativity, its claim can never be exploited fully. If the performative power of gender is indeed not only repressive, but productive, if power calls into existence what it names, and if power itself is shifted from a subject position and seen as reiterative action which can in its reiteration never precisely and accurately duplicate the act, the possibility emerges for an expropriation of the term which can never be a complete appropriation. ${ }^{7}$ As such the performativity of gender avails itself of the available possibilities in which power acts as discourse, acting within the very discursive regimes it opposes, yet not in any type of continuity, such as a consequence or reaction, but in discontinuity and disruption. ${ }^{8}$

Miranda Joseph is a participant in the roundtable discussion published by Christina Crosby, Lisa Duggan, Roderick Ferguson and Kevin Floyd, see bibliography.

7 Butler (1993:241) also uses the term 'expropriation' but the perspective from which she writes is that of the subject whose decentring entails becoming a kind of managing conduit for the flow of words.

$8 \quad$ See Butler (1993:241). 
Perhaps Winer and Young depict this tension the best when they intend to trace the history of queer theory "in terms of an interplay between a centrifugal drive away from sociality and a centripetal pressure towards sociable belonging and linkage. We recast the question of queerness as, before anything else, a question of social bonds coequally constituted by the corrosive and adhesive pressures of eroticism. Queer bonds, we suggest, are what come into view through the isometric tension between queer world-making and world-shattering, naming a togetherness in failures to properly intersect, the social hailing named by recognition as well as it radical occlusion" (2011:223-224), and later again "[q]ueer is at once disabled and inventive sociality" (226). The same tension is again expressed by Butler (2011) albeit from the perspective of the social boundedness of the body. There is for her a kind of 'intertwining' where the body "never fully belongs to itself." It has not chosen its way of entry into this world, does not know the names of those who created it, and constantly comes up against a world that is not of its own creation.

\section{Problematising the Queering of Biblical Texts}

In investigating the intersection between 'things queer' and religion, Schneider (2000) cautiously warns that Queer theory may not always be the most helpful tool for gays, lesbians, bisexuals and transgendereds in their debates with religion. He points to the legitimating use of religious discourses in the formation of identity which consequently allows "the strongest residual prohibitions against homosexuality continue to reside primarily in religious doctrine" (7). Furthermore, instead of functioning as sites for revolt and liberation, religious discourses have for two millennia actually been complicit in "establishing norms that support this heritage" (7). This obviously does not exclude religious discourse from being an object of study for Queer theorizing; on the contrary, owing to its complicity in the structuring of social hierarchies and its underlying normativities, Queer theory should not bypass the role of religion in naturalising, yes even divinising normativities. However, despite imaginative interpretations of a gay liberationist's faith in an " Act-Up' kind of Jesus who preached appallingly radical kindness and transgressed all sorts of rules about who should be in or out" (11), the "objects of religious faith can never be resolved enough to matter in the ways that the subjects of faith can" (11). Despite recognising the necessity of critical cooperation between Religious Studies in its various expressions and Queer Studies, Schneider appears to warn against slipping too easily between the two spheres and cautions towards regarding religious discourse not as solving a particular problem, but rather as part of the problem. ${ }^{9}$

Also from a theological perspective, Lowe (2009) situates the inclination to ask what the Bible says about same-sex relations to an earlier period of lesbian/gay theology production (50). As such the search is then for an interpretation that is closer to truth, the assumption being that newer methodologies, a wider span of disciplinarity, a deeper reservoir of interpretive tools and terminologies can excavate what lies concealed, and what lies concealed would be truth. A kind of apologetics then emerges where possible references to same-sex are reduced to a very small number, and then explained in terms that would presumably make the taboo enunciaiton more acceptable. For example: Lowe points to how early lesbian/gay theology interpreted Pauline vituperation against same-sex relations as referring "to a temple cult, prostitution, or even pederasty." And the sin of Sodom narrated in Genesis 19 becomes "cultic homosexuality or the sin of violent

Jordan (2012) is also concerned over the neglect of Queer theorists in interacting with religion and theology and he strongly suggests that it might be ascribed to disciplinary inhibitions, which only allows the dangerous remnants of theologies and religious discourses to flourish unabatedly. 
inhospitality to strangers," rendering a verdict that the Bible "takes no direct stand on the morality of homogenital acts nor on the morality of gay and lesbian relationships." 10 Although Lowe criticises this approach, she succumbs to the same practice when she takes Goss to task from lack of engagement with queer theories incorporating the notion of 'discourse and subjection' because this, according to her, "could provide an interesting way to interpret not only the person and work of Jesus Christ, but also his resistance to powerful discourses" (55). The objective of this type of approach is to find traces of what could be 'queer' in the Bible itself. What happens however, is that this type of investigative approach becomes an apologetics, again for certain subjects as the primary originators of knowledge, these subjects being those that have been made heroes and models for centuries and have been formally and institutionally catapulted into sources of life knowledge during the nineteenth century. Furthermore, the way in which power in antiquity has structured gendered hierarchies and normativities is not subjected to scrutiny, allowing the possibility for its replication.

It stands to reason that Jesus would be a prime target for queering which is not necessarily problematic depending on how it is done as will be seen. For Althaus-Reid and Isherwood (2007:310) however, the incarnation of Jesus constitutes the epitome of Queer Theology. They appear to find this moment of queerness in "the screaming baby born amidst cow shit and fleas, covered in his birthing blood and received into the uncertain arms of his child/mother," a moment that with the exception of the 'cow shit and fleas' probably happens in the lives of all human beings. ${ }^{11}$ But can this be seen as a moment of dissent? Even if we were to enter 'theology-speak' and find here a transgression between the divine and the human, the divine is never entirely forsaken - the 'archives' available for this story all attempt their utmost to link this boy with a rather patriarchal God father. In addition (again within the ambit of 'theology-speak'), the incarnation anticipates the crucifixion and the crucifixion signifies the most violent of all human act, namely the sacrifice of a child, an act that even repulsed the Romans! Yet institutional violence characterised the Graeco-Roman world from which this belief derived, a far cry removed from a destabilisation of societal structures. ${ }^{12}$

Yet as appeals resound constantly for finding women in biblical texts, for demonstrating how gender was produced, for pointing to ways of liberation and emancipation, for queering, warnings are issued concerning the dangerous impact, effects and discursive violence these texts may wrought upon contemporary society. Listening sceptically to heralding calls of politically active Christians in the U.S proclaiming the necessity of a 'Native American Theology of liberation,' Robert Warrior (2005) draws an analogy between the conquering Israelites versus conquered Canaanites and colonialist America versus colonialised Native America, emphasising the inappropriate, almost offensiveness the Exodus narrative as model for liberation would entail for Native Americans. Mary Ann Tolbert (2005) questions the weight of political gains when biblical citations or interpretations are compared to the "overall claims of biblical authority to promote the harassment and the oppression of millions of people?" She shows how bodies materialised

10 Lowe, 'Gay, Lesbian, and Queer,' 50, refers here and quotes from the work of Daniel Helminiak, What the Bible really says About Homosexualiy (San Francisco: Alamo Square, 1994), 107-108.

11 Within the paradigm of this type of work, it is not at all clear to me what legitimates the selection of material. Why, for example, is no reference made to Mary who is retained a virgin after having given birth, thereby approximating masculinity within a one-sex model, while at the same time assuring a 'pure' Jesus, no reference made to the insemination by the Spirit, all signifiers of a radicalised, hegemonic patriarchal system?

12 A more sophisticated treatment is rendered by Sheffield (2008) who points to the transgressive possibilities of the chalcedic body of Jesus. 
as 'others' can be infused with 'evil' making their condemnation and destruction even into eternity a celebratory occassion (13) and concludes that a failure to recognise how the Bible can reproduce domination and violence "is an ethical lapse of enormous consequence" (14). In a similar manner Ellen Armour (2011) refers to the damage appeals to biblical authority has done in the minds and bodies of her LGTBQ students, evoking the problem of responsibility over the "fraught status of 'the Bible' in ongoing debates over the status of sexual minorities" (1). Marchal (2010:204) refers to the warnings of both Krister Stendahl and Elisabeth Schüssler-Fiorenza whose use of 'health' as metaphor may signify the intense effect these texts may have upon bodies (but see also 206 and 208). It becomes clear that there are also very clear concerns on whether the Bible lends itself to the ameliorisation of contemporary conditions.

Another problem that must be taken into consideration as caveat in exploring the possibility of queering biblical material is what Dale Martin (2006) has identified as the myth of textual agency. Textual agency, also in manifestation in the study of the Bible emerges from Foundationalism. Foundationalism must be distinguished from Fundamentalism. The problem in this case is not to establish an equation between text and reality as if the text provides us with a window on real events and persons; neither is the problem to elevate the text to a source of inerrant statements providing prescriptions for moral and ethical behaviour. Foundationalism is a product of Modernism in which reality is taken to be stable and fixed. Whether it concerns the social, or the historical, the psychological or the textual, there is a possibility to gain true knowledge from the varieties of reality, the only problem being to find a paradigm, a mode of interpretation helping us to expose what lies stable and fixed in the reality we wish to investigate (2006:2-3).

According to Martin, it is Foundationalism that created the myth of textual agency. Textual agency locates the authority of meaning within the text. It makes use of a trope we have often heard, where the text is personified as having the capacity to 'speak,' to 'have a voice,' or allow the biblical text to 'tell us.' And we, as interpreters on the other hand, we have to listen to what the text says, or we have to discover what or find the meaning of the text. Although this type of interpretation abounds in the public's use of the Bible, it can also be found in the variety of interpretative procedures within the academic study of the Bible. More sophisticated versions of a foundationalistic interpretation of the text can be to use literary critical methods, or structural analyses distancing yourself in order to find particular principles in the text which would convey its meaning. Yet another approach would be to consider the text as repertoire of data, of evidence reflecting the social world of that text and providing us via sociological and so-called scientific methodologies to arrive at the meaning of the text. The primary or diagnostic component of Foundationalism is to premise a fixity, stability within the text, a fixed meaning, fundamentals or principles that can be read from the text, or that the text itself yields relative to the possibility of sanitised, neutral or objective modes of interpretation (2006:2).

It is Martin's contention to demonstrate that the myth of textual agency has sprouted a complete rhetoric of enquiry which in the academic study of biblical material centred around historical criticism in the belief that such a common (in the manner of universal) mode of interpretation will yield the same or at least closely affiliated meanings...which it did not (2006:17). However one argument was to differentiate contemporary from ancient culture, exposing the difference in cultural assumptions, thereby pointing to the dangers inherent in appropriating ancient culture for the solution of modern problems. Different assumptions informed different cultures rendering contemporary appropriation problematic (19). It could mean that biblical condemnation of homosexuality can be completely discarded owing to the radical degree of difference between 'them' and 'us.' In another 
instance it could lead to the differentiation between what is seen to belong to the 'core,' 'heart,' 'centre,' of Scripture and what could be relegated to the margins. In a case like this, biblical condemnation of Scripture can then be relegated to the margins and thereby discounted. ${ }^{13}$ Another argument compares scriptural passages and play them off against each other. This would make it easy to discard certain passages from the Hebrew Bible, or even Paul while pointing to others that could more readily be appropriated in contemporary culture (22). Yet another strategy would be not to counter, but to explain away or argue that this is not actually what the text is 'about'(22). In similar manner we could strategise to shift the focus away from the rigid fixity of the text to what the author must have meant, approximating the intention of the author, albeit in almost typological fashion as aligning with what the author, given the assumptions of his time must have meant (23). The use of narrative principles but without consideration of context is another strategy used, as is also the strategy that an author is simply quoting another text which means that it does not necessarily reflect his meaning (24-25).

According to Martin the problem with the myth of textual agency is that it shifts accountability away from the interpreter to the text, thereby releasing the interpreter from taking an ethical position, and acknowledging that it is not texts that mean, but "[p]eople mean with texts." He concludes: "[f]oundationalism is ethically dangerous. Foundationalism often leads to unethical practices because it masks the very real interpretive agency of the human interpreter and thus allows the interpreter to avoid responsibility for the truth, goodness, morality and social effect of her or his interpretation. Moreover, the modern method of historical criticism - though certainly a useful tool - cannot be depended on to deliver secure ethical interpretations of Scripture" $(1,2,16)$.

Martin's identification of the myth of textual agency is helpful, but it would be possible to go a bit further. Behind the desire to tap biblical writings, or to return to the Bible for an answer to contemporary issues, specifically with reference to sexuality, lie the remnants of the nineteenth century elevation of the subject as the primary originator of knowledge. It is for that reason that the tropical 'speaking of the text' and the 'listening of the hearer' can be deployed. It is for that reason, that intentions of authors are investigated; it is for that reason that meaning is located within the speaking text, and it is for that reason that historical criticism has been used in interpreting the text. It is for that reason also that a specific corpus of texts are used as founding material, as sources, as canon while others do not feature at all.

If our theorising of sexuality and gender were to recognise the agency of performativity a shift has to be made from 'text' and what these presumably would have meant, to discourse, since it is performative agency which defines texts as social practices, generated by fundamental social principles.

\section{What to Consider when Gender Performativity operates as Articulating Principle}

From the text of the Bible to biblical discourse

\footnotetext{
There are aspects of Martin's argument in this case I do not understand. That we should not relativise culture as if it is 'just culture' or the 'husk' of culture that can be dispensed with is correct because everything we do is indeed culture, and what is regarded as nature is culture. But it is problematic to depict a radical differentiation of culture in which reference is made to the unacceptable assumptions of biblical culture or the inventions of contemporary culture that are anachronistically imposed upon ancient culture as a discard of culture. As a matter of fact, pointing to 'homosexuality' as an invention of the late nineteenth century cannot be seen as dispensing with culture, but rather as taking culture seriously.
} 
If the performativity of gender is to function as principle of articulation in helping us think 'politics' with biblical material, the focus has to shift from the Bible as text to biblical discourse. Enquiring the Bible as discourse via a performativity of gender implies investigating particular relations of power that acted not only in the formation but also in the performance of discourse. How power as reiterated acting has constructed sexual normativities, how relations of power through their repetition have sedimented sexual hierarchies to function as expressions of naturalness and normality, how power via discursive practices have constructed and maintained normative ideals of the body, shift into focus. Enquiring biblical discourse is less concerned with what a biblical writing said about gender, sexuality or the body, than with what it did and does.

Instead of enquiring as to the meaning of the text, the text is seen as the product of particular practices operating in the control, selections, organisation and distribution of biblical statements. Without diminishing its importance, it becomes a miniscule element in a wide array of social practices that have not only effected its production, brought it into existence, but they also maintain its production as it becomes deployed in different contexts. It is already clear how its stability is completely dissolved in this dynamic process of production and constant reproduction. Just consider its moment of production. The vocabulary it used, is not of its own making, but has been paradigmatically selected from an already available socio-cultural linguistic repertoire and syntagmatically arranged according to prescribed grammatical rules and principles. The rhetorical strategies that have been deployed derive from the transference of socio-cultural values according to indexes and mechanisms of privilege and available valorisations, that were not the creation of the author or the text. Even the perspective from which a text is written, is not that of the author, but is the product, the end-result of a process of selection deriving from available opportunities. Referring to the role of the judge in citing the law, Butler (1993:225) writes that "it is through the invocation of convention that the speech act of the judge derives its binding power."

Once it has been produced it is kept in circulation by public institutions such as churches, in particular departments of religions, seminaries, but also schools, publishing houses, media, such as television hosting particular programmes on the Bible, but it can also be kept in circulation by politicians, by motivational speakers, by popular magazines, by literary works. ${ }^{14}$ However, these practices do not need to function on the same level; they need not be institutionalised or public but may also function on a more concealed, and therefore more effective level. It can also be those practices that constitute a modern household where a demarcation of roles may be fixed, where Bible readings happen as part of a family tradition. It can even be more private pertaining to the body itself, such as what a woman or a man should wear, or how a woman or a man should conduct her/his body they may even invade the intimacy of a person or a couple's sex life. Mills (2003:54) writes: "Rather than seeing discourse as simply a set of statements which have some coherence, we should, rather, think of a discourse as a existing because of a complex set of practices which try to keep them [the statements] ${ }^{15}$ in circulation and other practices which try to fence them off from others and keep those other statements out of circulation." It becomes clear that if 'queering' is to be taken as the performativity of gender whose concern is a critique of socio-political conditions operating in what communities will take as 'normal' or 'natural,' and if the biblical text itself has been deprived of its agency, the

\footnotetext{
14 See for example Mills (2003:54) who, in an attempt to make sense of Foucault's diverse views on discourse, refers to the wide variety of spheres where the Bible or biblical material are distributed and maintained.

15 My interpolation.
} 
shifting of the focus to 'discourse' compels an enquiry of discursive practices producing sexualities and gender.

Furthermore, looking at the Biblical writings from the perspective of discourse, compels a consideration of how these regulated, power-invested statements structure what communities take to be their reality, because it is discourse in its continuous deployment that constructs what we take to be reality. Foucault once remarked that "we should not imagine that the world presents us with a legible face, leaving us merely to decipher it; it does not work hand in glove with what we already know; there is no prediscursive fate disposing the word in our favour" ([1971] 1972:229). The practising of discourse intervenes distortingly and violently, and makes the world we deem our reality. The human body does not escape this re-birth, this cultural construction. Being discursive, biblical writings have long lost what they have never had in any case, namely an original meaning. This myth is only resurrected where their intervention in the making of social reality has been made into a necessity. The intervention in the making of social reality, does not reflect reality, does not 're-make,' or 'reproduce' reality, but makes, creates, produces what we take to be the realities of our lives. There is therefore little sense in a constant search for an ever-evading meaning (we are talking here of approximately almost 2,500 years in which this has been going on, and it is actually a bit arrogant to assume that any of us will be able to unfold the real meaning of any biblical text). When Genesis 1-2, the numerous levitical laws referring to purity, Paul's letters, or deutero-pauline material - such as the letter to the Ephesians are discussed in terms of discourse, then it becomes clear how these texts have structured our reality in terms of gender and sexuality, and why this has become possible.

The qualifier 'regulated' refers us to the appearance of the power relations within which these statements have been and are deployed. I find it difficult to express with what force relations of power at work avail themselves of these texts in their exertion of control and distribution. It would almost be more correct to argue that they are dissolved in the mechanisms that structure our realities; with such power has the intervention, distortion, violation taken place that we have become unaware of its effect on our daily lives and in our daily practices. However, there is another justification for using the word 'dissolved,' besides the fact that we do not have an original, these statements have often functioned as acts in a variety of usages and contexts, from the reading in Greek of a text portion at the opening of a conference to the readings at early morning military parades; from the use of a passage as the Word of God to its use as substantation for the maintenance of gender hierarchies in public magazines. Whatever the case may be - how relations of power affirm on the one hand, but exclude on the other hand where the biblical text is summoned - must be part and parcel of the biblical scholar's work.

If the queering of biblical material is to expose and enact the peformativity of gender in a way that will destabilise categories and mechanisms of normalisation and naturalisation, the agenda must be to identify and demarcate those practices operating in the processes of normalisation. This is exemplified in the work of Halvor Moxnes in his resignification of the historical Jesus programme (2003). According to Moxnes Jesus can be seen as queer owing to the unsettling qualities of his identity (5). However to have arrived at the conclusion of 'unsettledness', Queer theory compelled enquiry into the 'places' of identity construction in the world of Jesus, or to put it a bit differently the 'normative landscape' that was supposed to determine his identity (15). As such, Moxnes was tasked to investigate the gendered normativities at work in the household, in particular those concerned with a young man $(25-29,38-43)$, but also in the case of moulding identities that have forsaken the compulsory link with the space of the household (49-53), thereby also requiring the need to 
investigate other practices concerning masculinity and manhood, such as the discourses concerning the 'eunuch' (72-73; 78-80, 84-90), 'asceticism' as male space (76-78; 80-84). Not being part of places invested with hegemonic masculinity also necessitated an enquiry into the normativities that constructed the spaces of the asexual, that is, barren women and children (91-101). What makes the work of Moxnes remarkable and even more unique within Jesus studies from which a radical departure is made in any case, is the manner in which the performativity of gender is deployed in also exposing the normativities by means of which Historical Jesus scholarship has done their 'objective,' and more recently 'scientific' analyses of Jesus, ${ }^{16}$ thereby allowing 'queering' to function simultaneously on two levels, the time of Jesus, as well as the world of current scholarship. ${ }^{17}$

The work of Moxnes is an example of how Queer theory may provide us with the framework of moving away from textual agency to an enquiry of biblical discourse, how a heroic Jesus, as product of $19^{\text {th }}$ century scholarship and agent in the shaping of his own destiny can acquire a change of identity when put into the places where power as discursive practices functioned as identity constitutive, how the performativity of gender pervaded, constituted and normativised identity, desires, institutions and everyday life in antiquity. But whatever the degree of 'unsettledness' the identity of Jesus might have entailed, history has 'settled' him quite firmly in hegemonic discursivities demanding investigation into how performativities of gender has symbolised him in to the 'normalising' of contemporary masculinities. How this may function will be, inter alia, be seen in the next section.

\section{Discontinuity, Disruption, Dissent as Interrogating Strategy in the Queering of Biblical Discourse}

There is a radicality made available by the critical framework offered by Queer theory of which the neglect would be nothing short of betrayal! Exposing the performativities of gender must at the same time be the enactment of disruption and dissent. It is not simply the identification of ancient or contemporary constitutive normativities, the definition and demarcation of discursive practices, it is something entirely different than a 're-imagining,' a 're-reading' of, or even worse a 're-listening' to the biblical text. 'Queering' biblical discourse is motivated by a political agenda which may expose the historical vulnerability of contingencies. This may render biblical discourse, in particular biblical texts, not as sites where instances of normative disruptions may have occurred in moments of unwitting enlightenment, but rather in its entirety problematic and constitutive of heteronormativity. Distinguishing herself from the radicality of queering as done by some exponents of biblical Queer studies Kamionskowski (2011:132) aptly formulates: "By positioning themselves [Stone, Epstein and Runions] as interrogators, they consciously stand 'outside' to chip away at the 'centre.' The political and social agenda of bringing down heteronormativity (an agenda that I share), is the primary aim of these authors and it seems to me that the biblical text and other cultural media are tools, or the means by which the political agenda is addressed." There are several implications to this formulation. Firstly, it

16 See for example the location of this approach within colonial framework (4), the patriarchal, male and continental domination of its space, as well as it temporal origins in the $19^{\text {th }}$ and $20^{\text {th }}$ centuries (4), its ideological moorings in Modernity $(7-8,10-11)$ and the ensuing search and discovery of the model for manhood in the unique hero, Jesus $(11,16,22,24)$, the refusal to perceive how Jesus' conduct "to callously turn his back on his cultural and family obligations" would have been seen as the transgression of a taboo (65-67).

17 A similar approach can also be found in Hester (2005), where the discursive practices of not only early Christianity, but also those at work within the ancient world in the production of gender, are accessed. 
confirms the act of 'queering' as a "political performance of gender that will enact and reveal the performativity of gender in a manner that destabilizes" cultural engendered normativities. Secondly, it recognises and acknowledges (even from a perspective privileging preservation rather than repudiation) how biblical discourse has permeated the socio-cultural fabric of society, co-operating in the construction of heteronormativities. Thirdly, it removes the queering of biblical discourse from the compulsion of the disciplinary regime to the wide and nebulous sphere of culture and politics, enacting a particular political accountability and commitment - biblical discourse has indeed become 'culturalised' operating sometimes very explicitly, while in other instances in a concealed and taken-for-granted manner.

In the first section I have indicated how a tension exists in the use of the term 'queer.' While it can never fully belong to itself, but exists within the very social structures and relations of power that have produced it, while it cannot shirk its sociality, its diagnostic feature is that of radical resistance. Queering is less concerned with liberation or emancipation, less concerned with being uploaded and being integrated into a community's identities, that is, less concerned with the bestowal of normality, than with resisting the very conditions that have constructed normality, the very performativities of gender that have created particular fixed identities. Queering does not simply expose the normativities that produce and shape gender, does not only point to the relations of power and the conditions that make gender perform, but it also inverts the flow of power, resists and dissents. To put it a bit differently for the sake of clarity: The agenda of queerness is not to "join the old boys' club" via an exposure of valorisation-differentials, but to resist not only the existence of the 'club,' but also to subvert, undermine and change the engendered normativities that have institutionalised such an exclusion.

The power relations that acted as biblical discourse, whether during the time of its origins, or at later phases up to at least the late eighteenth century, did not allow for what has since been called 'heteronormativity.' As a matter of fact, the relations of power that produced gender during antiquity can more likely be seen to derive from phallocraticism, the reign of the phallus and normativities constructed from a 'one-sex model' (Laqueur 1990). It has become a popular pastime of biblical studies scholars in attempts of queer recovery to propose Galatians 3:28 as an example, specifically referring to the erasure of gender boundaries. However, a performative such as this performs by virtue of citation (as Butler has taught us - 1993:225), it is through the invocation of the norm, the convention that the act brings a particular condition into existence. If Galatians 3:28 is seen as performative, it cites the normativities of a 'one-sex model,' driven by the regulatory power of the phallic discourse in which the male body was seen to be the criterion of perfection. Yes, there will be 'neither male nor female' because all will be transformed to 'maleness.' Far from propagating egalitarian gender ideals, the exact opposite was the case. If the performativity of gender was enacted by the normativities of a 'one-sex model,' this functioned as the domain in which the relations of power that structured and maintained gender hierarchies acted as discourse, in our case biblical discourse. The pervasiveness of phallocraticism in biblical discourse is such that the problematics of its appropriation in contemporary society should be made into a constant task of scholarly deliberation, instead of attempts at 'dephallogisation.'

Biblical scholars operating from Queer Theory are well aware of this problem, but there are degrees of difference in the manner the tension between dissent and the inevitable reappropriation of biblical discourse emerges. For some, such as Moxnes (2003), the objective still remains to discover moments of queerness in biblical discourse and the act of 
dissent is then displaced to its first century actualisation. It would also be possible to locate the work of Jeremy Punt $(2006,2007,2008,2010,2011)$ within this paradigm. In pioneering the intersections between Postcolonial and Queer Theory, he also grapples with the problem of Galatians 3:28 (2010), correctly indicating (after revisiting its history of interpretation - 143-145) that it was not initially seen as a charter for the liberation of women or a token of egalitarianism (145), neither did it function as a critique on heterosexual marriage (149). On the contrary, it should indeed be read in terms of the cultural commonplaces and conventions that yielded these binaries, because a reading independent of these would not have been possible (146). Throughout the article it is conceded that this statement cannot be extricated from its hegemonic, patriarchal moorings and he also concludes with: "Paul did not invest Gal 3:28 with emcancipatory or egalitarian meaning; in fact, constantly re-invoking the three binaries throughout Galatians and elsewhere suggests that he largely maintained the practices and values that were accepted as normal in his culture" (162). He also makes room for the view that what may be interpreted as androgynic for modern readers, was probably more an attempt to masculinise the female body (151-154). To that extent his problematisation disrupts the continuities proposed by contemporary renderings of gender performativities using Galatians 3:28. However, the tension and the inclination towards affirmation rather than aggressive disruption emerges when a tendency to rescue the text can be seen in "a certain inclusive thrust in the text" (145), when marriage relations were not suspended, but that Paul's performative could have had a "possibly serious destabilising effect" (149), maintaining also that "the text is remarkable disavowal of the given, the normal, the conventional" (156), that the statement can be seen as an initiation of "transgression of gender, sexual and socio-political boundaries as they were constructed in the first century," and when he concludes that not being able to find an appeal to the equality of women in this text does not necessarily mean "the end of the road for a liberatory or even constructive reading of Gal 3:28" (162). For Punt, it is especially in the manner Paul destabilised via the formula 'in Christ,' that the queering of the binary relations can be seen to take place (159).$^{18}$ One of the problems this approach will have to take into consideration, is the possibility that the subject, whether it be Paul or Jesus, may again surface as the primary, pristine originator of knowledge as remnant of the $19^{\text {th }}$ century male heroes, and that with this resurrection the hegemonic phallocraticism infusing current sexual normatives may still function as resource for contemporary heteronormativity.

The degree of dissent emerges more intense in the work of Runions (2011). Runions exposes why there is often such deep-seated 'disgust' is often felt for an alternative ethnic group or race. Bringing Queer, Postcolonial Theory and insights from Cultural Studies on affect into conversation, she demonstrates how biblical discourse has been complicit in a persistent "racialization through sexualization and nonheteronormativity." Her point of departure in recounting the story of Rahab "is that the contemporary disgust against nonheteronormative sexuality in the United States is conditioned by the racialization of certain representations of sexuality in the Bible, even where the biblical heritage and/or

\footnotetext{
I have used Punt's work here owing to the consistent maintenance of this tension between disruption and appropriation, but there are several others working within this field in a similar manner, such as Townsley (2011) where the appeal on Romans 1:23-28 as a constemporary mechanism to exclude gays and lesbians is thwarted by linking Paul's statements on what is taken as same-sex desire to the goddess religions of his environment. In this respect (Romans 1:18-32) see also Punt, who finds in Paul's argument an appeal to acknowledge God, but Paul's view on same-sex desire as ambiguous (2008). See also Punt (2011:334-335) again for maintaining this tension, as well as his alignment with Moxnes (335-337).
} 
racialization is no longer obvious" (45). What can be called 'racial-boundaring' has usually taken place by the summoning of what was constructed as sexual deviance, is not unique to biblical discourse, but neither can (and should) the profound complicity of biblical discourse in the formation of different cultures be denied. If the degree of power acting as religious discourse, universalising the homogeneity of the 'self' in contest with the 'other,' - its constant reiteration in different contexts and eras of colonialisation, its instantiation as a 'script' of propriety that can only be aspired to, never being able to fully fulfill by virtue of some inherent or innate defection - if these, are the conditions of its performativity, the Bible indeed becomes a 'dangerous' document. If one adds to these the intensity of power that has become concealed, the task of the exposure and subversion of biblical discourse as performative in causing injury becomes a necessary response to the accountability of every biblical studies scholar.

In similar vein, but with an even more incisive cut, Hornsby (2011) illustrates how biblical discourse operates in concealed (or perhaps not that concealed!) ${ }^{19}$ complicity with contemporary forms of power deployment. She argues that biblical discourse (and she focuses especially on Pauline material) acts as power, producing gender normatives for neoliberal capitalism which can be seen as currently the dominant power, investing in the construction of the docile, productive body. She exposes how capitalism, in its more recent postmodern, neoliberal expression craves an increase in profitable output with fewer bodies, constructs sexual normatives allowing for a wider diversity of sexualities and genders. The heteronormativity that was necessary for a previous phase for capitalism can now be discarded in favour of more fluidity concerning sexualities. What has become imperative for capitalism is the construction of an identity that is voluntarily submissive, that is less in need of external regulation, but is marked by a "heigtened and internalized "will to submit"" (2011:14). What is the target, is a docile, subservient body," a masochistic identity committed to self-sacrifice, but who can simultaneously operate under the illusion of freedom. Biblical discourse, not only via the Pauline interpretation of the death of Jesus, but also through current interpretations, whether that be in film, academic biblical criticism or popular, spiritual literature, provides the gender normatives to construct a masochistic body through mimesis, formed by the glorification of suffering, obedience, humiliation and self-deprivation. She concludes that "[b]ecause of the needs of dynamic and global capitalism, perceptions of modern Christianity aid in producing docile bodies - bodies that submit to power while being under the illusion of sexual freedom. The bodies, no longer required to reproduce sexually, can wander within wider, more elastic sexual and gender boundaries; that's the good news." However this fluidity in gender boundaries comes at a price - these identities "must be willing, no eager to suffer for this elasticity" (153).

The degree of dissent may vary among proponents working within the intersection of biblical discourse and Queer theory, but it must be present and function as operating principle in the critique of performativities of gender as they destabilise and subvert the processes of naturalisation and normalisation. The process of queering does not stop once the exposure and subversion have been done, as power is constantly reproducing itself in new configurations, the normatives producing normality are constantly scrutinised.

\section{Conclusion}

- It has been argued and shown that the process of queering indeed compels thinking 'politics' in the engagement with biblical discourse. It requires the exposure of how

19 Reference is made inter alia to Mel Gibson's The Passion of Christ (2011:143-144). 
relations of power construct performativities of gender that normalise and naturalise bodies, while at the same time prompts towards its subversion and undermining. In the queering of biblical discourse more than one approach can be followed, but the condition of radical dissent, of disruption and the production of difference must function as articulating principle, in order to investigate the degree of complicity with dominant forms of power, whether that pertains to its operation during the first century $\mathrm{CE}$, during consecutive eras or in its contemporary appropriation. Exposure and disruption of how phallocratic gender normatives have infused biblical discourses and how these have been appropriated in complicit interaction with contemporary materialisations of the body have become part of the biblical critic's task, thereby necessitating transdisciplinary enquiry.

- 'Queering' requires a discursive approach to the Bible. Shifting the focus from text to discourse prevents the myth of textual agency from infusing texts with fixity and stability, creating the illusion of the meaning that has to be searched for and recovered in a variety of ways. In a similar way does the move away from the meaning of the text to discourse demolish the subject as primary originator of meaning. When the notion of 'text' occupies centre position in opposition to 'discourse,' an illegitimate link with the author remains. A move from 'text' to 'discourse' requires a removal of the author and I would submit that claims on the appropriation of engendered approaches such as Queer Studies that continues the link with the author are self-contradictory. When an author (any author) produces a writing, s/he avails him/herself of the contemporary available literary strategies, whether that be in oppositional or affirmative mode. If that were not the case, communication would not have been possible. Yet, as soon as it leaves her hand, it is again dissolved in the discursive practices of its day, taken up to be controlled, to be distributed, to function in exclusionary mode or to be advocated in the affirmative. Every statement is subject to different modes of control, it can be dissected, taken out of context, cited in situations no-one could have imagined. It is against this background that it would also be possible to speak of the 'disappearance of the author.' The author no longer functions as authority for the text. When biblical material is shifted to the sphere of the discursive, it is not only the agency of the text, but also the agent who have to be problematised in light of forcefulness of relations of power. When the author in biblical studies is then still foregrounded, the question is whether it is not yet again an attempt to establish continuity thereby making a last futile attempt to locate agency within the text. It may be good practice to heed the warning of Brown (2011) made in conjunction with the contributors to the volume Bible Trouble. In concluding he writes that the one thing which binds them together despite the dazzling array of different approaches is the "cautionary phrase, 'Be careful.' Each of the authors, in his or her way, applauds the growing acceptance of LGBT individuals in the larger society as well as queer theory's advancement in the realm of biblical studies. Nevertheless, each strikes a cautionary note" (343). 


\section{BIBLIOGRAPHY}

Althaus-Reid, M and Isherwood, L 2007. "Thinking Theology and Queer Theory." Feminist Theology 15(3), 302-314.

Armour, Ellen T 2011. "Queer Bibles, Queer Scriptures? An Introductory Response." Pages 1-8 in Bible Trouble: Queer Reading at the Boundaries of Biblical Scholarship. Edited by TJ Hornsby and K Stone. Atlanta: Society of Biblical Literature.

Arondekar, A 2005. "Without a Trace: Sexuality and the Colonial Archive." Journal of the History of Sexuality 14(1/2), 10-27.

Brown, MJ 2011. What Happens When Closets Open Up? A Response. Pages 343-352 in, Bible Trouble: Queer Reading at the Boundaries of Biblical Scholarship. Edited by TJ Hornsby and K Stone. Atlanta: Society of Biblical Literature.

Butler, J 1993. Bodies That Matter: On the Discursive Limits of "Sex." New York and London: Routledge

Butler, J 1999. Gender Trouble: Feminism and the Subversion of Identity. New York and London: Routledge.

Crosby, C, Duggan, L, Ferguson, R and Floyd, K 2012. “Queer Studies, Materialism, and Crisis: A Roundtable Discussion.” GLQ: A Journal of Lesbian and Gay Studies $18(1), 127-147$.

Edgardh, N 2009. “Difference and Desire - A Queer Reading.”Dialog: A Journal of Theology 48(1), 42-48.

Foucault, M 1972. “The Discourse on Language.” Pages 215-37, in The Archaeology of Knowledge \& The Discourse on Language. Translated by AM Sheridan Smith. New York: Pantheon Books. Delivered originally as lecture at the Collège de France on December 2, 1970, the first translation was published in 1971, Social Science Information, 7-30.

Garton, S 2004. Histories of Sexualities. New York: Routledge.

Giroux, HA with Shannon, P 1997. "Cultural Studies and Pedagogy As Performative Practice: Toward an Introduction. Pages 1-9, in Education and Cultural Studies: Toward a Performative Practic. Edited by HA Giroux with P Shannon. New York and London: Routledge.

Handley, WR 2005. "Belonging(s): Plural Marriage, Gay Marriage and the Subversion of 'Good Order.' Discourse 26(3), 85-109.

Hester, DJ 2005. "Queers on Account of the Kingdom of Heaven: Rhetorical Constructions of the Eunuch Body." Scriptura 90(3), 809-823.

Hornsby, TJ 2011. “Capitalism, Masochism, and Biblical Interpretation.” Pages 137-155, in Bible Trouble: Queer Reading at the Boundaries of Biblical Scholarship. Edited by

TJ Hornsby and K. Stone. Atlanta: Society of Biblical Literature.

Jakobsen, JR 2012. "Perverse Justice.” GLQ: A Journal of Lesbian and Gay Studies 18(1), 19-45.

Jordan, MD 2012. "Religion Trouble.” GLQ: A Journal of Lesbian and Gay Studies 13(4), 563-575.

Kamionskowski, S.T 2011. "Queer Theory and Historical-Critical Exegesis: Queering Biblicists - A Response." Pages 131-136, in Bible Trouble: Queer Reading at the 
Boundaries of Biblical Scholarship. Edited by TJ Hornsby and K Stone. Atlanta: Society of Biblical Literature.

Laqueur, T 1990. Making Sex: Body and Gender from the Greeks to Freud. Cambridge: Harvard University Press.

Loughlin, G 2008. "What is Queer? Theology After Identity." Theology and Sexuality 14(2), 143-152.

Lowe, ME 2009. "Gay, Lesbian, and Queer Theologies: Origins, Contributions, and Challenges." Dialog: A Journal of Theology 48(1), 49-61.

Marchal, JA 2010. "Giving an Account of a Desirable Subject: Critically Queering Graduate Biblical Education.” Pages 199-212 in, Transforming Graduate Biblical Education. Edited by E Schüssler-Fiorenza and KH Richards. Atlanta: Society of Biblical Literature.

Martin, DB 2006. Sex and the Single Savior: Gender and Sexuality in Biblical Interpretation. Louisville and London: Westminster John Knox Press.

McIntosh, M 1968. “The Homosexual Role.” Social Problems 16(2), 182-192.

Mills, S 2003. Michel Foucault. London and New York: Routledge.

Meyer, JD 1997. "Profane and Sacred: Religious Imagery and Prophetic Expression in Postmodern Art.” JAAR 65(1), 19-46.

Moxnes, H 2003. Putting Jesus in His Place: A Radical Vision of Household and Kingdom. Louisville and London: Westminster John Knox Press.

Punt, J 2006. “Queer Theory Intersecting with Postcolonial Theory in Biblical Interpretation. Bulletin/CSSR 35(2), 30-34.

Punt, J 2008. "Sin as Sex or Sex as Sin? Rom 1:18-32 as First Century CE Theological Argument.” Neotestamentica 42(1), 73-92.

Punt, J 2010. "Power and Liminality, Sex and Gender, and Gal 3:28."Neotestamentica 44(1), 140-166.

Punt, J 2011. "Queer Theory, Postcolonial Theory, and Biblical Interpretation:

A Preliminary Exploration of Some Intersections." Pages 321-341 in, Bible Trouble: Queer Reading at the Boundaries of Biblical Scholarship. Edited by TJ Hornsby and K Stone. Atlanta: Society of Biblical Literature.

Runions, E 2011. "From Disgust to Humor: Rahab's Queer Effect." Pages 45-74, in Bible Trouble: Queer Reading at the Boundaries of Biblical Scholarship. Edited by TJ Hornsby and K. Stone. Atlanta: Society of Biblical Literature.

Rubin, G 2010. "Blood under the Bridge: Reflections on 'Thinking Sex'." GLQ: A Journal of Lesbian and Gay Studies 17(1), 15-48.

Schneider, LC 2000. "Homosexuality, Queer Theory, and Christian Theology." Religious Studies Review 26(1), 3-12.

Sheffield, T 2008. "Performing Jesus: A Queer Counternarrative of Embodied Transgression." Theology and Sexuality 14(3), 233-258.

Townsley, J 2011. "Paul, the Goddess Religions, and Queer Sects: Romans 1:23-28." JBL 130(4), 707-728.

Tolbert, MA 2005. “The Reproduction of Domination.” Union Seminary Quarterly Review 59(1-2), 9-14. 
Warrior, R 2005. "Canaanites, Cowboys, and Indians." Union Seminary Quarterly Review $59(1-2), 1-8$.

Weeks, J 2005. "Remembering Foucault." Journal of the History of Sexuality 14(1/2), $186-201$. 